Article

\title{
Incorporating Virtual Reality into the Teaching and Training of Grid-Tie Photovoltaic Power Plants Design
}

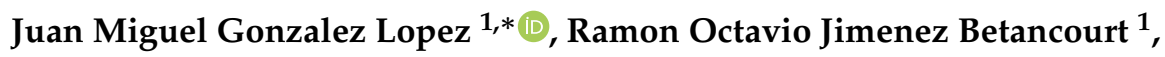 \\ Juan M Ramirez Arredondo ${ }^{2}$, Efrain Villalvazo Laureano ${ }^{1}$, (1) and Fernando Rodriguez Haro ${ }^{1}$ \\ 1 Electromechanical Engineering Department, University of Colima, Colima 28860, Mexico; \\ rjimenez@ucol.mx (R.O.J.B.); villalvazo@ucol.mx (E.V.L.); ferharo@ucol.mx (F.R.H.) \\ 2 CINVESTAV Unidad Guadalajara, Guadalajara 45019, Mexico; jramirez1502@gmail.com \\ * Correspondence: jgonzalez71@ucol.mx
}

Received: 06 September 2019; Accepted: 18 October 2019; Published: 23 October 2019

\begin{abstract}
The current difficulty in obtaining financial resources to acquire equipment for training personnel and the requirement of well-trained engineers in the industry looking toward sustainability, creates an opportunity to innovate in teaching tools, such as the proposed in this article, where a virtual world is projected, integrating the planning and design of a photovoltaic power plant (PV). The user can interact while immersed in the virtual scene as if the PV system were already installed, illustrating technical characteristics of selected equipment and its installation details, while the user is interacting with didactic activities focused on visual, auditory, and kinesthetic learning. This paper summarizes an initiative within the teaching-learning context, which aims to show the advantages of using modern tools, such as virtual reality, to achieve teaching goals in a renewable energy course.
\end{abstract}

Keywords: virtual training; virtual reality; teaching innovation; virtual photovoltaic planning; educational technology

\section{Introduction}

Renewable energies have a noteworthy development worldwide. The International Renewable Energy Agency (IRENA) reported an increase of $8.8 \%$ in power generation with renewable energy in 2016 where hydraulic is the predominant one [1]. According to [2], in the last decade, the installed capacity of solar technology grew annually, with an average of $36.3 \%$, in Mexico. This document foresees an annual average growth of about $21.1 \%$ in the photovoltaic solar generation capacity to be installed from 2017 to 2031 with an increase in the annual average rate of $29.3 \%$. In Mexico, solar energy is an abundant resource, [3] estimates incident solar energy in the northeast of Mexico by an empirical model; while the global solar resources along the Gulf of Mexico were assessed by [4] confirming that this region offers a great solar potential. The incident solar radiation in the country is quantified in [5] with the mean irradiation estimated to be around $5.5 \mathrm{kWhm}^{-2} \mathrm{~d}^{-1}$. Thus, these data encourage sustainable projects in the country in the medium-term. Therefore, well-trained and experienced personnel are needed, and the universities are the principal leaders in a position to prepare the students to enter the industry and train personnel, but the high costs of didactic equipment for teaching is unachievable for most public universities in emerging nations, such as in Mexico. Therefore, new training and education strategies are emerging, especially the use of virtual reality (VR) technology, whose use is growing dramatically.

There is no doubt that the new generations of students have a great facility for the use of multimedia elements, which normally presents an attractive educational space, and motivates them 
to continue using them. These media allow the ability to analyze and produce visual messages, while being attractive and didactic for the students. The literature reports significant advances in this direction. Hence, VR has been explored in many topics including tourism [6,7], medicine [8], improving creativity $[9,10]$, and in engineering [11,12]. Thus, allowing the students and trainers to attract their attention, breaking the monotony of classical teaching, learning concepts or processes to solve problems, provide maintenance, and implementing practices in a safe environment, as if the students were immersed in the industry. Consequently, it would even be possible to face real technical dilemmas in their operation preparing them for future eventualities without spending a fortune on their purchase and maintenance, simply by maintaining them virtually. That is the intended purpose for the contribution of this paper: to be able to train engineering students in the installation of a photovoltaic farm, using the technological advances of VR that are available to us.

\section{Related Work}

Most of the required trained-personnel are qualified and able to use special software or didactic equipment to analyze the performance of planning and designing of projects worldwide. In the literature, [13] describes the creation of a freeware simulator to consider photovoltaic studies on residential applications. Petros [14] calculates the accuracy of some software to compare them using a real grid-connected photovoltaic installation. A strategy using project-based learning to teach photovoltaic systems is proposed [15] using SketchUp software, similarly, the Energy3D simulator is designed for sketching up a realistic-looking structure [16], but these proposals are based on the modeling and do not discuss technical aspects.

Teaching should be complemented with strategies where the students can play a more active role, discovering concepts, while building and transforming their knowledge, and developing abilities required in the industry. Mavrikios [17] discusses the learning methodology of a teaching factory (TF) - to combine the studying with working realistic situations to promote significant learning. [18] proposes the use of a 3D holographic system using a real size virtual replica, and by using mobile devices integrated into the factory and in the classroom, while Centea [19] implements a dual education system collaboration between industry and university to train students and employees involving TF. Another tendency is the use of mixed reality in learning about factories as suggested in [20], displaying information about on-site working environments [21]. The problem for the MR use is when no equipment exists or the training needs to be implemented in safety situations without risking trainers and equipment [22], such as the presented case.

In the case of VR related to electrical energy education, Salah [23] presents a visualization method based on VR to familiarize students with Industry 4.0. Elmira [24] describes the capacity of an interactive world which can contribute to designers, planners, and to comprehend the roles of design strategies in building a smart city. Lopez [25] presents the design and construction of an experimental wind turbine, with a capacity of less than $5 \mathrm{~kW}$. Likewise, in [26], the authors propose the development of virtual reality simulation software for designing a wind farm by modifying individual parameters of the wind turbine, such as blade length and angle, as well as the spacing and amount of wind generators. Bobadilla [27] presents a VR application for underground line operators in a distribution power system. Similarly, [28-30] present a tool to understand and improve the skills of students in providing maintenance in distribution power line networks. Chiluisa [31] describes an application of a hybrid power plant for professionals in electrical power systems training, allowing the ability to interact through a mathematical model and enabling the manipulation of dependent variables, bringing out a more realistic background in a substation, while [32] describes a similar situation for an auto-transformer installed in an electric power substation to perform maintenance and operating procedures.

In the context of photovoltaic systems, some applications of VR training have been proposed. The initial advances are described by Veldhuis [33], where VR allows the ability to visualize irradiance calculations on multiple arbitrarily oriented surfaces, including the shadow simulation, however, 
other aspects of the construction of the photovoltaic power plant (PV) system are not addressed. The work of Hatzilygeroudis [34] presents developments for teaching principles of solar radiation and the fundamentals in the conversion to electric energy. But the presented tool is not applied in the design of the complete PV system. More recently, Ritter in [35] shows the development of the Mechanical Engineering Virtual Reality (MECH-VR) Lab at the Louisiana State University. This lab uses C\# in Visual Studio within the Unity game engine, and the avatar teacher animation created to provide a guided tour to teach only concepts without considering any technical aspects. Hence, this paper presents a VR tool that includes a complete technical vision regarding the details of how a solar plant may be installed, including accessories, electrical installation, mounting systems, and electrical protection, adopting the methodology of teaching factory designed in a VR tool, allowing the student to interact with a fictitious world, perform some solar panel connections, and allowing the ability to verify measurements of variables using safety equipment, while text and audio are displayed, explaining the technical aspects of the installation. Thus, this tool supports the teacher when no equipment exists to do a laboratory practice, providing a realistic experience about a medium-large scale photovoltaic system, reducing student learning times and increasing the amount of significant knowledge acquired with very similar results to those obtained with equipment in real laboratories.

\section{Proposed Methodology to Incorporate Photovoltaic Systems into Virtual Reality Planning}

The main purpose of the presented teaching methodology is to motivate the self-learning of students and immersing the student into the TF strategy. The tool supports the teacher, in the presented case, providing laboratory practices due to the lack of equipment, and contributes to the design of PV systems teaching.

The proposed methodology is depicted in Figure 1. It is broken down into three blocks,

1. The first one (from left to right) represents the PV designing and 3D objects drawing;

2. The second block denotes the virtual environment development, the application programming interface (API), and its interaction with the rendering software by sending messages between these blocks;

3. The third block denotes the user's action in virtual-interactions, which generates a state of decision.

The sizing PV systems can be done with the help of SketchUp software to model the buildings since it already has a plugin for the photovoltaic system. Additionally, it has a geographic location feature that allows designing 3D drawing with the incorporation of solar systems by doing a study to avoid shadows by optimizing the installed capacity of each building. In this case, the SketchUp files can be exported as a 3D object to be implemented in the virtual world (VW) with the help of Unity. Similarly, the mounting system is designed in SolidWorks and exported to Unity. The next step (in the second block) is to build roads, objects, trees, taking into account all possible losses due to the affectation of shades on the PV system, thus creating the virtual environment. Two programming languages were used: Unity Script, which is a programming language based on JavaScript and C\# for the implementation of the VW. The programming code and the integration of different tools allow the user to interact with the VW, inducing a decision state in the third block, creating a synchronous request between the API and the user decisions, resulting in changing the behavior into the virtual environment.

The use of the virtual concept provides a realistic experience where the user's action can affect the VR environment and may be linked to real-world actions. Incorporating VR into the PV planning projects gives to the user a near-real feeling that they can inspect, visit, and interact with the facilities. This allows for walking between the buildings of medium-large scale solar photovoltaic installation and participate in learning activities, such as inspecting solar panel characteristics, arrays connections, wire-gauges, electrical protections, and inverter main input variables. During these processes, the user 
can interact at each predetermined activity by reading boards, listening to audio, and inspecting the installation; at the same time, they can verify what is learned in each training lecture.

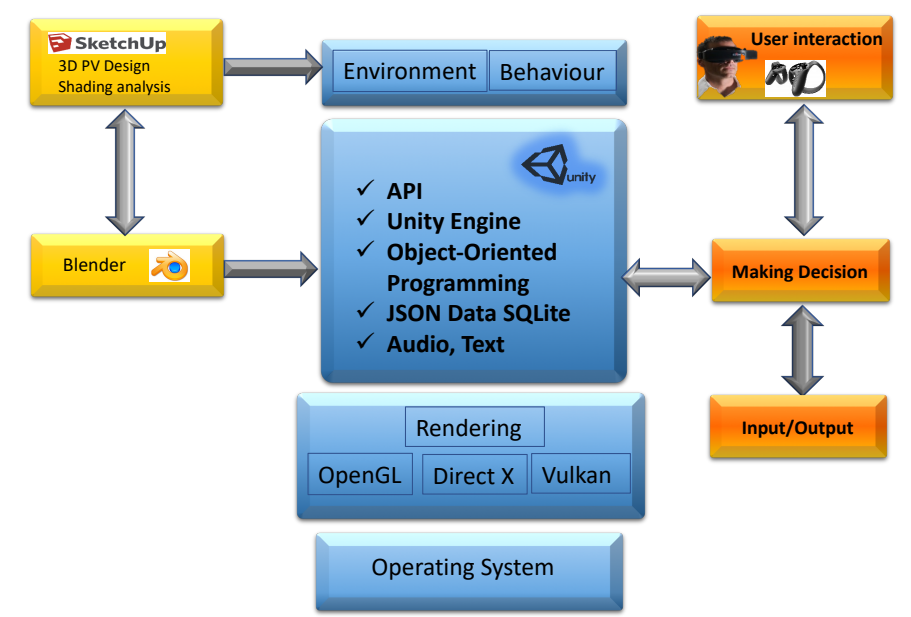

Figure 1. Proposed methodology for planning photovoltaic power plant (PV) in virtual reality (VR).

\section{Virtual Reality Planning}

For explanation purposes, the Electromechanical Faculty of the University of Colima, Mexico is considered as the case study, it is located at latitude 19.1239 and longitude -104.4001 . The installation is divided by buildings; each one is dimensioned according to its installed capacity, avoiding shadings. Figure 2 incorporates the 3D design of the $200 \mathrm{~kW}$ PV system. The user can virtually go through the facilities to be aware of details, permitting to interact with objects by clicking on the specific elements, such as the solar panel, to read its characteristics, like open-circuit voltage (Voc) and short-circuit current (Isc). Likewise for the voltage (Vmax) and current at maximum power (Imax), necessary for dimensioning the inverter and electrical protections.

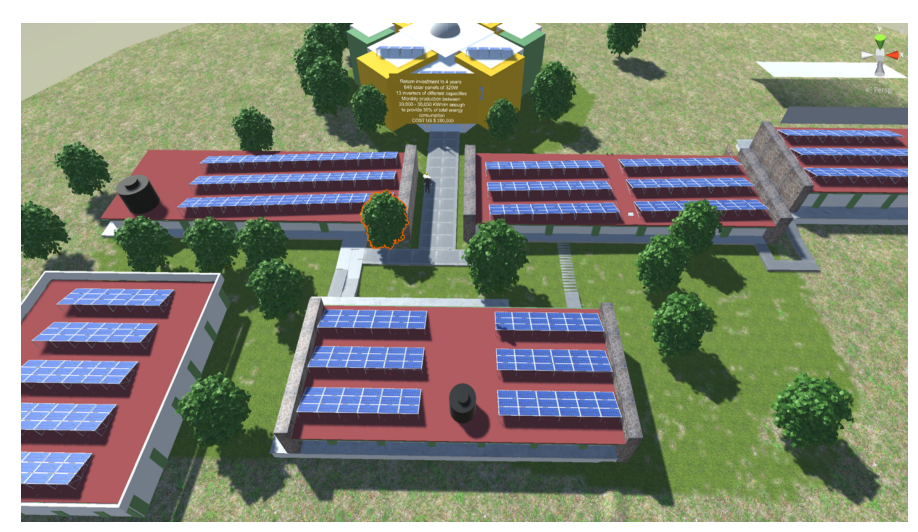

Figure 2. 3D planning installation of the $200 \mathrm{~kW}$ PV system.

The students do a supervision activity where they are capable to act independently in the facilities, during the inspection, they can verify solar array connections, analyze the one-line diagram, and to measure the principal electrical variables without forgetting the use of personnel protection. Figure 3 shows that the first activity is the selection of appropriate gloves, boots, and safety helmet to avoid any accidents.

Additional information may be obtained; for instance, the user can go to check the installation and get information about the system at each building. Figure 4 illustrates the user's view on a building, where it can be noticed that the solar panel characteristics are present on a text-board. At the same time, audio is explaining the selected features, such as the nominal power $320 \mathrm{Wp}$, open-circuit voltage Voc $=45.6$ Volts, and a short circuit current Isc $=9.1$ Amperes; additionally, the maximum power 
voltage, $\operatorname{Vmax}=37.4$ Volts and the maximum power current Imax $=8.56$ Amperes may be identified. The purpose is that the student can interact in a visual, auditory, and kinesthetic way to take into account the main variables when handling serial-shunt connections. In the case of the illustrated building Figure 5, there are 160 solar panels of $320 \mathrm{~W}$ and two $27 \mathrm{~kW}$ string inverters, with 80 panels connected to each inverter. The inverters have two maximum power point trackers (MPPT), so 40 panels are connected for each MPPT. Then, two parallels of $20 \mathrm{PV}$ are series-connected in such a way that $912 \mathrm{~V}$ is attained at the input inverter with $18.2 \mathrm{~A}$. In this activity, the student can verify the connection diagram by holding the user's hand and verifying their connections. The purpose of this activity is to obtain the input voltage and current variables to the inverter; these are also necessary to calculate the electrical protections on the DC side, such as fuses, fuse holders, circuit breaker, and surge protectors. During this activity, the amounts of needed material are also illustrated for the mounting system, in which the required rails, bolts, and accessories are explained. The purpose is to illustrate that every single detail is integrated into the project and that the student may verify it.

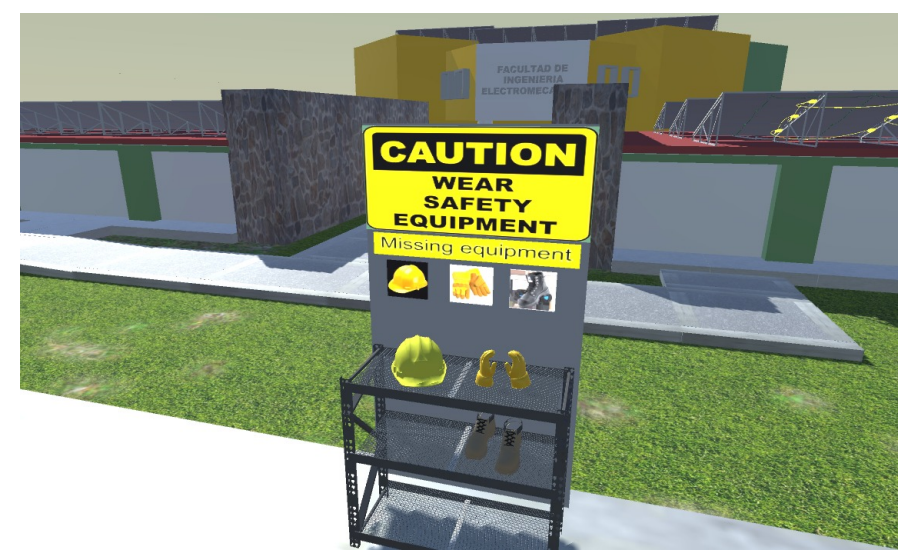

Figure 3. Personnel safety equipment.

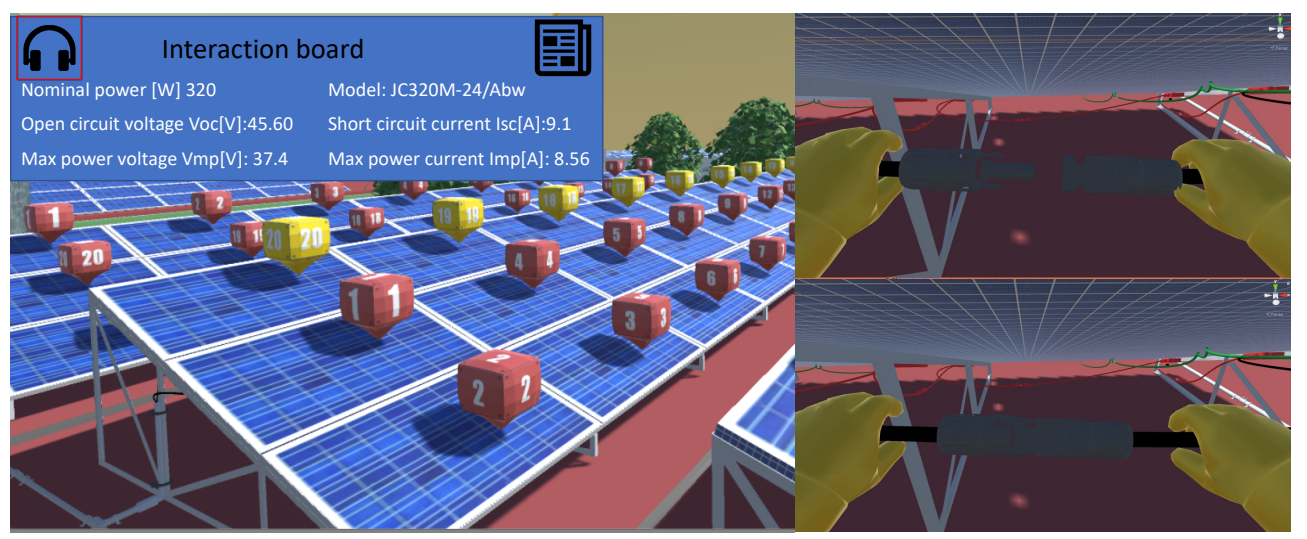

Figure 4. Connecting PVs and inspecting characteristics.

The student can follow the connections from solar panels through the electric pipes until they reach the combiner box and review its wiring. Then, through text and audio explanation about the function of each protection device, the DC fuse can be selected, considering international norms. Similarly, the surge protector from the high voltage lighting and DC breakers can be selected. Therefore, the wiring is depicted for training purposes. It is worth noting that this activity is explained both by audio and by text, while the user is interacting freely to learn the way these devices are selected. The protections on the AC side are also illustrated in the combiner box, Figure 6. The user can approach freely as much as he wishes to observe or measure the electrical connections between the fuses, circuit breaker, surge protector, and the output of the wire going to the MPPTs of the inverter. 
Similarly for the AC-side connections, while the user may observe the one-line diagram. Figure 6 also illustrates a current measure while using the personnel protection.

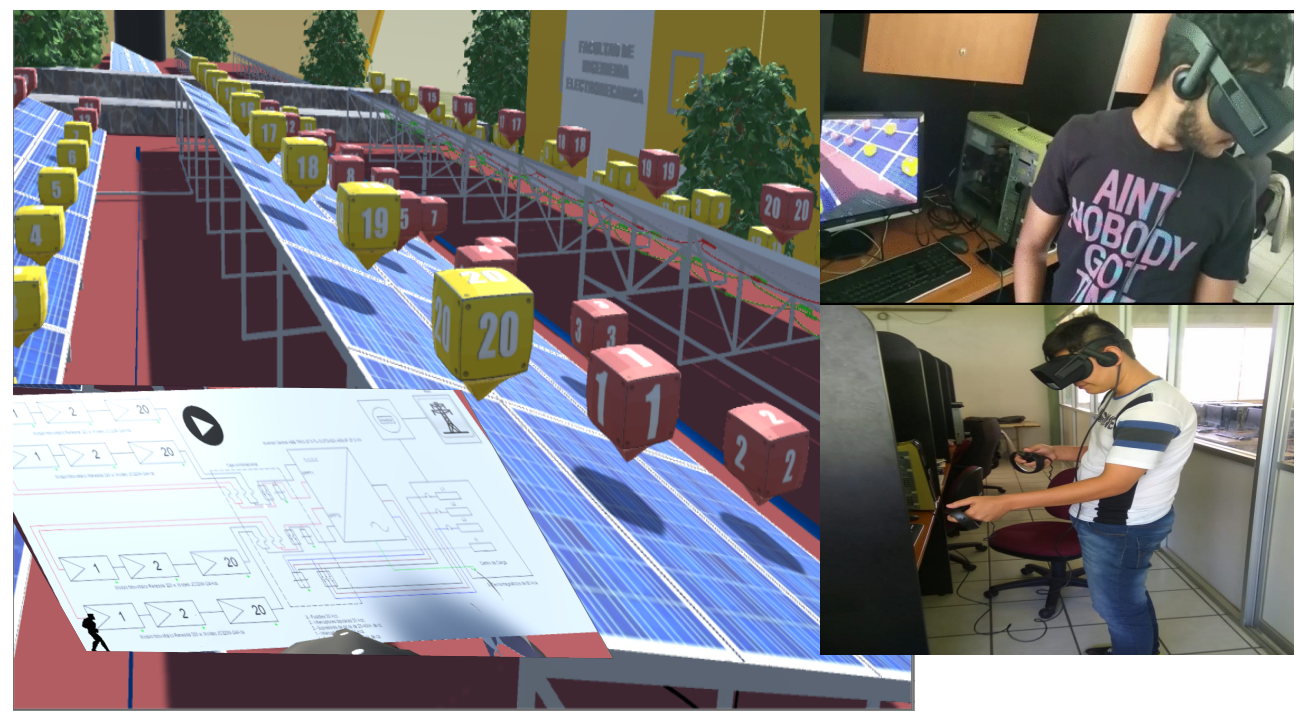

Figure 5. Supervising single line diagram for PV arrays connections.
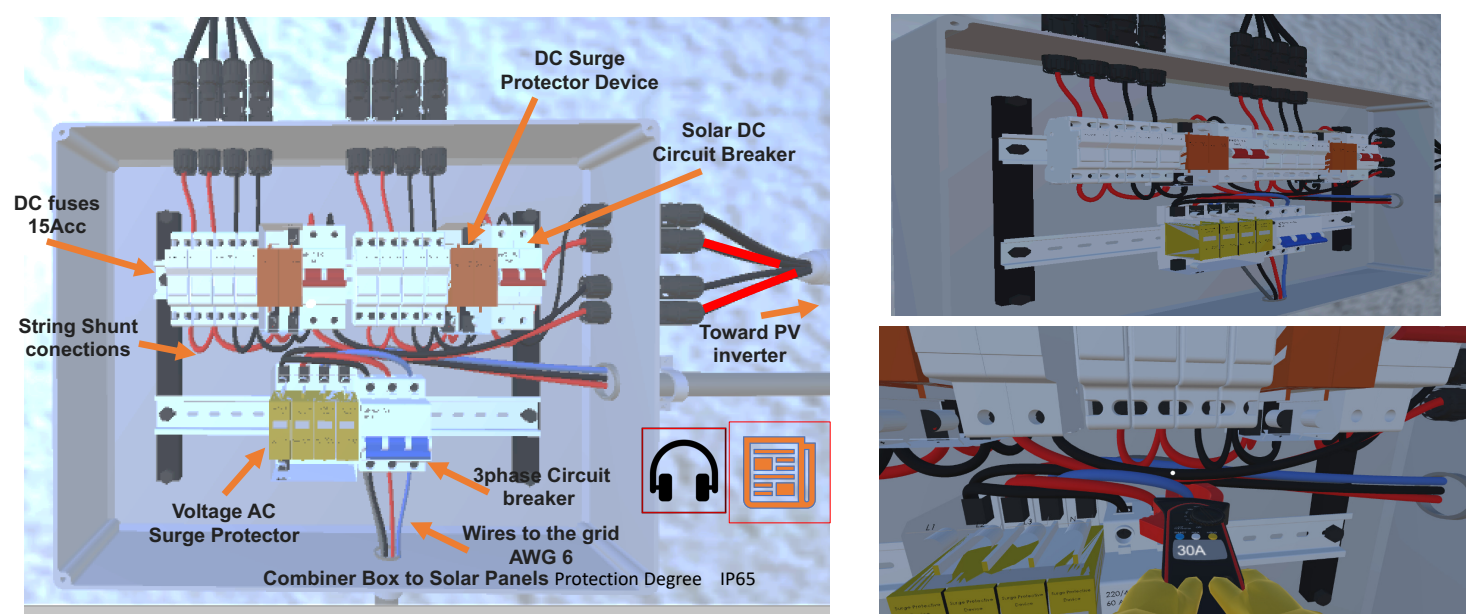

Figure 6. Combiner box installation.

Power generation of the installation is described in Figure 7. On this board, the sun has movement emulating its sunrise and sunset; while the sun is visible, its sun-path depicts the solar radiation on the solar panel. The energy injection is displayed dynamically, as a monitoring system would show the main variables, such as the power delivered in Watts over the day, as well as the energy in $\mathrm{kWh}$, these variables are obtained with the modelling of [36]. Although Figure 7 could be taught just with an infographics scheme, this activity seeks that the student understands the process of energy conversion in an animated way beside the inverter and at the interconnection point to reinforce how the waveforms vary with radiation. 


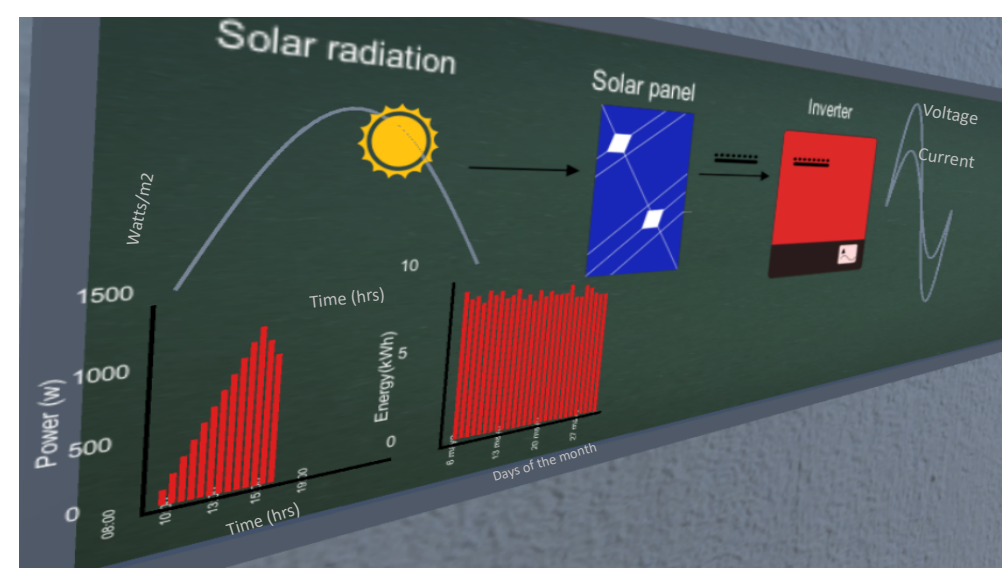

Figure 7. Emulating the PV system generation.

\section{Results and Discussion}

\subsection{Academic Context}

This training tool seeks to raise the abilities of the user to design and install a solar power plant properly, offering technical support in the details when selecting the suitable equipment that involves a project of this type.

The primary users of this development tool are the final year students in electrical engineering from the University of Colima, who are studying a course on renewable energies. Therefore, the fundamental theoretical knowledge has been taught to evaluate the usefulness of the designed virtual tool. The students are divided into two groups. The first, called traditional training (TT), implies traditional teaching using presentations, theory, and blackboard explanations. The second group is called virtual reality assisted training (VRAT). Table 1 illustrates all participants, including the average age of each group.

Table 1. Participant students.

\begin{tabular}{ccccc}
\hline & Students & Female & Male & Age \\
\hline TT group & 14 & $1(7.1 \%)$ & $13(92.9 \%)$ & 21.8 \\
VRAT group & 14 & $1(7.1 \%)$ & $13(92.9 \%)$ & 22.4 \\
Total & 28 & 2 & 26 & 22.1 \\
\hline
\end{tabular}

The teaching process is illustrated in Figure 8. For both groups, presentations are made for teaching theory, concepts, and selection of equipment for designing small/medium-scale photovoltaic plants during two sessions of $120 \mathrm{~min}$ in two weeks. During the third week, the activity was evaluated as it relates to designing a solar plant, taking into account electrical protection and mounting rail systems and all the required details. Then, during the fourth week, the TT group was asked to design a $30 \mathrm{kWp}$ solar plant; while the VRAT group began the use of the virtual world so that they took a tour through the facilities. Students were provided with an Oculus Rift used as virtual reality glasses, and a CPU Intel Core i7-870 @ 2.93 GHz with 8Gb in RAM, Windows 7 Home, and a graphics card (Geforce GTX 1050 Ti 4GB GV-N105TOC) that could be used in the classroom. The total average time devoted to navigation was $30 \mathrm{~min}$, gaining time while being more active. During the fifth week, for both groups, a test was carried out to evaluate the proposed tool; they were asked to design a photovoltaic solar plant of $50 \mathrm{kWp}$ taking into account all details.

Table 2 shows the evaluation checklist used to assess student performance during the third and fifth week. In both cases, the task is clear, design a PV plant that generates $30 \mathrm{~kW}$ and $50 \mathrm{~kW}$, respectively. The evaluations are carried out without internet access, so they are provided with data of solar panels and inverters in order to select the appropriate equipment for the required solar plant. 
The evaluations consider the job skills that the student will need in the industry; from the selection of equipment, design of photovoltaic arrangements, calculations of conductor sizes and protection devices, the use of personal protective equipment, and the amount of power generation taking into account the value of $5 \mathrm{hrs}$ of solar radiation typically used in the literature.

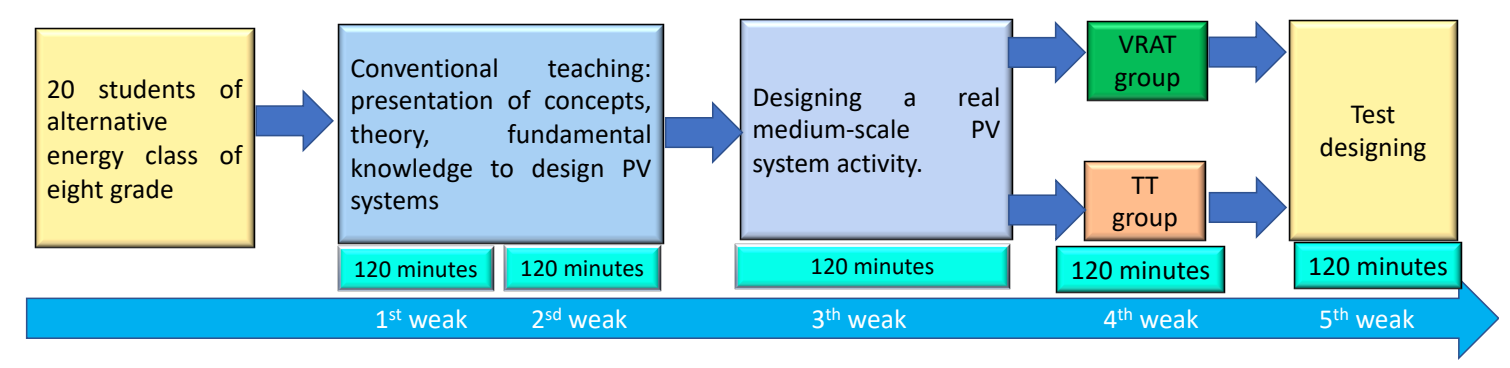

Figure 8. The experimental teaching process.

Table 2. Evaluation checklist.

\begin{tabular}{ccc}
\hline \multicolumn{1}{c}{ Instructions } & $\begin{array}{c}\text { Score } \\
\text { 0 worst; 10 = best }\end{array}$ & Comments \\
\hline 1 & Select the capacity and quantity of the solar panel \\
2 & Choice of the inverter according to electrical characteristics \\
3 & PV arrays design showing the Voc and Isc \\
4 & Illustrate Vin and Iin for the inverter \\
5 & Calculate the capacity of the electrical fuses \\
6 & Determine the capacity of the DC and AC switches \\
7 & Obtain the surge protections \\
8 & Calculate electric conductor gauge \\
9 & Obtain the monthly generation produced by solar PV system \\
10 & Mention of personal protection needs \\
\hline
\end{tabular}

\subsection{Statistics Analysis Results}

Table 3 illustrates the main statistics corresponding to the results of the test evaluation applied during the third week, and the final test in the fifth week to perform an Analysis Of Variance, determining significant differences between the acquired knowledge of both groups. The main results obtained out during the 3rd week illustrates no significant difference between the two groups $(p=0.532>0.05)$. Therefore, the students had equivalent knowledge before the use of the proposed tool. Once the experiment is carried out, it is worth noting that the experimental group VRAT completed the task in less time than the participants in the TT group, and the statistical analysis shows a significant difference $(p=0.008<0.05)$ illustrating the benefits of the teaching methodology based on virtual reality. One of the main advantages of using the VR system is that the participant can interact with the objects as in the real world, and provides a platform to learn by interacting in a visual, auditory, and kinesthetic way. Then, not only better knowledge is acquired, but the effectiveness of the use of time spent teaching is gained. Furthermore, Figure 9 depicts the increasing average on grades for both groups, emphasizing the effectiveness in the use of the VR tool.

Table 3. Participant students.

\begin{tabular}{cccccccc}
\hline \multicolumn{7}{c}{ 3th Week Activity } & \multicolumn{7}{c}{ Final Test } \\
\hline & Average & F & $p$ & Average & F & $p$ & Time \\
\hline TT group & 6.74 & 0.40599977 & 0.53202831 & 7.35 & 8.66918919 & 0.00801796 & 90 \\
VRAT group & 6.34 & & & 8.7 & & & 30 \\
\hline
\end{tabular}




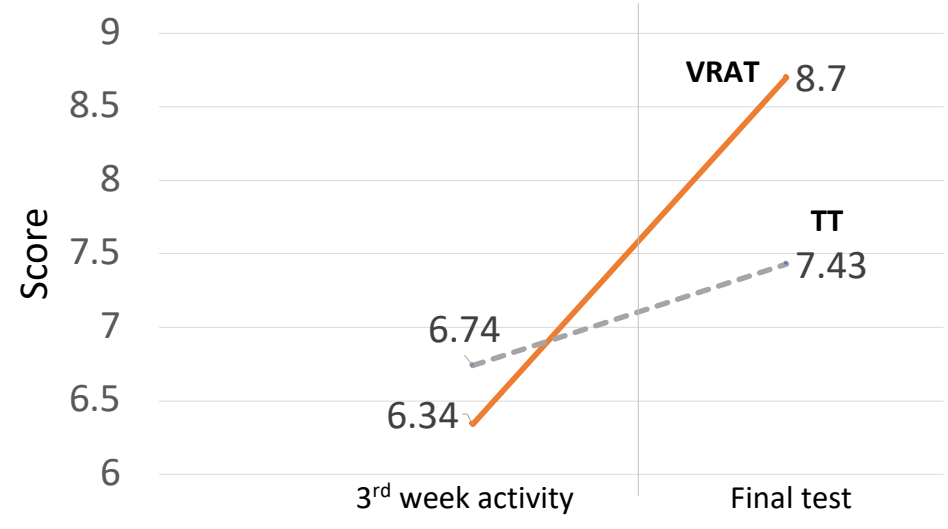

Figure 9. Knowledge improvement measurement.

\subsection{Assessment of Student Satisfaction}

An analysis was carried out through a satisfaction survey to evaluate the satisfaction of teaching based on virtual reality. For teaching, the attained results show that the virtual world can be quite efficient in time, and the students evaluated the activity positively. The results of the satisfaction questionnaire are summarized in Table 4. Students were asked to provide their feedback related to the design and their viewpoint about the methodology and acquired skills through the used tool. Also, they were asked to provide a grade from 1 to 5,5 being the best. Regarding the virtual world, $95.8 \%$ of the respondents agree that the exhibited virtual environment has no differences between the facilities of the faculty and the virtual world, except that the faculty does not have the photovoltaic system installed, however, the equipment is very similar to the real world. Students agreed with the rendering of the objects; individually, users suggested an improvement to the inverter textures was important, although this was not significant enough to generate confusion on the technical planning.

Most students think they could understand most textual descriptions and learned about the presented details in the virtual plant. They agree that the virtually designed scenes have adequate contents provided them with useful knowledge. The statistical results reveal that the scores, in this category, lie between 3.88 and 4.32 , while the overall average score is 4.12 .

Table 4. User satisfaction survey.

\begin{tabular}{|c|c|}
\hline Questionnaire & Score \\
\hline 1. Is the $\mathrm{V}$ world similar to the facilities at the faculty? & 4.83 \\
\hline 2. Are the virtual objects look like in reality? & 4.91 \\
\hline 3. Is it easy to operate the virtual environment? & 4.91 \\
\hline 4. Is the text clear in the VR? & 4.75 \\
\hline 5. Is the audio appropriate to the explanation during the virtual tour? & 4.66 \\
\hline 6. Using virtual labs enhances my understanding of the theory Classes? & 4.75 \\
\hline 7. Using virtual labs improves my professional practical skills? & 4.75 \\
\hline 8. The use of a world is useful for the teaching-learning of installing medium scale photovoltaic system & 4 \\
\hline Average $\quad 00$ & 4.8 \\
\hline
\end{tabular}

The virtual laboratory allowed them to understand and visualize all the technical details of the installation. However, some of them report feeling a bit dizzy after using the Oculus, and those who have visual problems were found to be uncomfortable with the Oculus as expected. Others say: "I found a class like this much more practical since you can understand and interact not only with the diagrams, but also with the real connections", and "It is a handy tool since it helps you to interact with the diagrams and understand the installations." 


\section{Discussion}

The main goal of this project is to develop a tool based on virtual reality, which helps to positively incentivize the teaching and learning process of an electrical engineering group of students at the University of Colima. However, the authors judge that the tool can be used with other engineering and related groups. The results presented in this paper, allow us to realize that, in general, students feel very comfortable with the tool developed, and show a desire to continue learning using this type of modern tools. The main elements that constitute the development are the VR lenses managed by the Unity software. This represents affordable equipment, thinking about extending the tool to other types of courses and areas of specialty. The increase of capacities shown by the students who used the virtual tool allows to foresee that the professionals graduated from the career are highly qualified, as the country and society require it. For this reason, it is, for the authors, an incentive to continue improving and expanding the virtual tool.

\section{Conclusions}

A virtual environment has been developed for the teaching and training of a photovoltaic power plant installation. The virtual environment was developed with the help of SketchUp and Unity; Sketchup facilitates the sizing of installed capacity for buildings using a 3D dimension, the designs of which were exported to Unity to create the virtual environment, and given a finish to the texture of the programmed objects. The survey result indicates that the planning of photovoltaic systems in a virtual environment can be a better way for presenting projects since they provide clear information on the technical issues of how an installation can be, as well as creating certainty about the initial required investment, since even the smallest details can be included, such as accessories. This type of virtual environment provided a more effective teaching time as well as improved their abilities and their knowledge.

Author Contributions: J.M.G.L. and R.O.J.B. planed the strategy and the investigation; J.M.R.A. gave the statistic analysis and reviewed the writing; E.V.L. and F.R.H. contributed with materials and VR programming; J.M.G.L. and J.M.R.A. wrote and edited the paper.

Funding: This work was supported by SEP-Mexico under the program NPTC-PRODEP.

Conflicts of Interest: The authors declare no conflict of interest.

\section{References}

1. Scheer Hermann, The International Renewable Energy Agency IRENA. IRENA . Available online: http: //www.irena.org/ (accessed on 20 October 2018).

2. Secretaria de Energia, Prospectiva de Energias Renovables 2017-2031. Secr. Energ. Available online: https: //www.gob.mx/cms/uploads/attachment/file/284342/Prospectiva_de_Energ_as_Renovables_2017.pdf (accessed on 12 June 2017).

3. Rivas, D.; Saleme S.; Izaguir, O. A climatological estimate of incident solar energy in Tamaulipas, northeastern Mexico. ELSEVIER Renew. Energy 2013, 60, 293-301. [CrossRef]

4. Hernandez, E.Q.; Rodríguez, G.E.; Saldaña, F.R.; Fernández, A.; Manzano, F. Solar energy resource assessment in Mexican states along the Gulf of Mexico. Renew. Sustain. Energy Rev. 2015, 43, 216-238. [CrossRef]

5. Gutierrez, T.A. Attenuation processes of solar radiation. Application to the quantification of direct and diffuse solar irradiances on horizontal surfaces in Mexico by means of an overall atmospheric transmittance. Renew. Sustain. Energy Rev. 2018, 81, 93-106. [CrossRef]

6. Yu, M.F.; Chun, L. The Usability Testing of VR Interface for Tourism Apps. Appl. Sci. 2019, 9, 1-11.

7. Tussyadiah, I.P.; Wang, D.; Jung, T.H.; Dieck, M.C. Virtual reality, presence, and attitude change: Empirical evidence from tourism. Tour. Manag. 2018, 66, 140-154. [CrossRef]

8. Guazzaroni, G. Virtual and Augmented Reality in Mental Health Treatment. In I IGI Global Core Reference Title in Medical, Healthcare, and Life Sciences; Università Politecnica delle Marche: Ancona, Italy, 2019; ISBN 13: 9781522571681 
9. Molina, C.R.; Pertegal, M.; Jimeno, M.A.; Mora, M.H. Virtual Reality Learning Activities for Multimedia Students to Enhance Spatial Ability. Sustainability 2018, 10, 1074. [CrossRef]

10. Li, H.H.; Sun, H.; Tsai, T.H. Research on 3D Painting in Virtual Reality to Improve Students' Motivation of 3D Animation Learning. Sustainability 2019, 11, 1605.

11. Manzano, E.S.; Manzano, A.F. The Higher Education Sustainability through Virtual Laboratories: The Spanish University as Case of Study. Sustainability 2018, 10, 4040. [CrossRef]

12. Vergara, D.; Rubio, M.; Lorenzo, M. On the design of virtual reality learning environments in engineering. Multimodal Technol. Interact. 2017, 1, 11. [CrossRef]

13. Gonzalez, J.M.; Pouresmaeil, E.; Cañizares, C.A.; Bhattacharya, K.; Mosaddegh, A.; Solanki, B. Smart residential load simulator for energy management in smart grids. IEEE Trans. Ind. Electron. 2019, 66, 1443-1452.

14. Petros, J.A.; Emmanouil, D.F.; Konstantinos, G. Accuracy analysis of software for the estimation and planning of photovoltaic installations Int. J. Energy Environ. Eng. 2014, 5, 1-7.

15. Gonzalez, J.M.; Salome, J.; Morales, E.; Betancourt, R.; Contreras, L.; Perez, M. Project-Based Strategy for teaching photovoltaic considering 3D simulation tools and natural phenomena. Int. J. Electr. Eng. Educ. 2019, 100, 1-8. [CrossRef]

16. Xie, C.; Schimpf, C.; Chao, J.; Nourian, S.; Massicotte, J. Learning and teaching engineering design through modeling and simulation on a CAD platform. Comput. Appl. Eng. Educ. 2018, 26, 824-840. [CrossRef]

17. Mavrikios, D.; Papakostas, N.; Mourtzis, D.; Chryssolouris G. On industrial learning and training for the Factories of the Future: A conceptual, cognitive and technology framework. J. Intell. Manuf. Spec. Issue Eng. Educ. 2013, 24, 473-485. [CrossRef]

18. Mavrikios, D.; Alexopoulos, K; Georgoulias, K.; Makris, S; Michalos, G.; Chryssolouris, G. Using Holograms for visualizing and interacting with educational content in a Teaching Factory. Procedia Manuf. 2019,31, 404-410. [CrossRef]

19. Centea, D.; Singh, I.; Elbestawi, M. SEPT Approaches for Education and Training using a Learning Factory. Procedia Manuf. 2019, 31, 153-158. [CrossRef]

20. Li, W.; Nee A.; Ong, S. A state-of-the-art review of augmented reality in engineering analysis and simulation. Multimodal Technol. Interact. 2017, 1, 17. [CrossRef]

21. Juraschek, M.; Butha, L.; Posselta, G.; Herrmann, C. Mixed Reality in Learning Factories. Procedia Manuf. 2018, 23, 404-410. [CrossRef]

22. Akbulut, A.; Catal, C.; Yıldız, B. On the effectiveness of virtual reality in the education of software engineering. Comput. Appl. Eng. Educ. 2018, 26, 918-927. [CrossRef]

23. Salah, B.; Abidi, M.H.; Mian, S.H.; Krid, M.; Alkhalefah, H.; Abdo, A. Virtual Reality-Based Engineering Education to Enhance Manufacturing Sustainability in Industry 4.0. Sustainability 2018, 11, 1477. [CrossRef]

24. Jamei, E.; Mortimer, M.; Seyedmahmoudian, M.; Horan, B.; Stojcevski, A. Investigating the Role of Virtual Reality in Planning for Sustainable Smart Cities. Sustainability 2017, 11, 2006. [CrossRef]

25. López, H.M. Diseño y Construcción de un Aerogenerador Experimental con Capacidad Menor que 5 kW y Desarrollo de Software de Simulación en Realidad Virtual con Fines Didácticos. CEMIE-Eólico. Available online: http:/ / cemiee.iie.org.mx/Proyectos/Proyecto-P08 (accessed on 5 May 2017).

26. Abichandani, P.; Fligor, W.; Fromm, E. A cloud enabled virtual reality based pedagogical ecosystem for wind energy education. In Proceedings of the 2014 IEEE Frontiers in Education Conference (FIE) Proceedings, Madrid, Spain, 22-25 October 2014; Volume 11, p. 1477.

27. Galvan, B.I.; Ayala, G.A.; Rodríguez, G.E.; Arroyo, F.G. Virtual reality training system for the maintenance of underground lines in power distribution system. In Proceedings of the Third International Conference on Innovative Computing Technology (INTECH 2013), London, UK, 29-31 August 2013; pp. 199-204.

28. Arendarski, B.; Termath, W.; Mecking, P. Maintenance of complex machines in electric power systems using virtual reality techniques. In Proceedings of the Conference Record of the 2008 IEEE International Symposium on Electrical Insulation, Vancouver, BC, Canada, 9-12 June 2008; pp. 483-487.

29. Perez-Ramirez, M.; Arroyo-Figueroa, G.; Ayala, A. The use of a virtual reality training system to improve technical skill in the maintenance of live-line power distribution networks. Interact. Learn. Environ. 2019, 27 1-18. [CrossRef]

30. Araujo, R.T.S.; Araujo, M.E.S.; Medeiros, F.N.S.; Oliveira, B.F.C.; Araujo, N.M.S. Interactive simulator for electric engineering training. IEEE Trans. Educ. 2016, 14, 2246-2252. [CrossRef] 
31. Chiluisa, M.G.; Mullo, R.D.; Andaluz, V.H. Training in Virtual Environments for Hybrid Power Plant. In International Symposium on Visual Computing; Springer: Cham, Switzerland, 2018; pp. 193-204.

32. Barata, P.N.A.; Ribeiro-Filho, M.; Nunes, M.V.A. Consolidating learning in power systems: Virtual reality applied to the study of the operation of electric power transformers. IEEE Trans. Educ. 2015, 58, 255-261. [CrossRef]

33. Veldhuis, A.J.; Reinders, A.H. Real-time irradiance simulation for pv products and building integrated pv in a virtual reality environment. IEEE J. Photovolt. 2012, 2, 352-358. [CrossRef]

34. Hatzilygeroudis, I.; Kovas, K.; Grivokostopoulou, F.; Palkova, Z. A hybrid educational platform based on virtual world for teaching solar energy. In Proceedings of the EDULEARN14 Conference, Barcelona, Spain, 7-9 July 2014; pp. 522-530, ISBN 978-84-617-0557-3.

35. Ritter, K.A., III; Terrence, L.; Chambers, P.E. PV-VR: A Virtual Reality Training Application Using Guided Virtual Tours of the Photovoltaic Applied Research and Testing (PART) Lab. In Proceedings of the 126th Annual Conference and Exposition, American Society for Engineering Education, Tampa, FL, USA, 18 June 2019.

36. Mathworks. Available online: https://la.mathworks.com/help/physmod/sps/examples/single-phase240-vrms-3500-w-transformerless-grid-connected-pv-array.html (accessed on 18 June 2019).

(C) 2019 by the authors. Licensee MDPI, Basel, Switzerland. This article is an open access article distributed under the terms and conditions of the Creative Commons Attribution (CC BY) license (http:/ / creativecommons.org/licenses/by/4.0/). 